\title{
Solvent Effects on the Conformations and Hydrogen Bond Structure of Partially Methylated $p$-tert-Butylcalix[4]arenes
}

\author{
Leo C. Groenen, ${ }^{a}$ Erich Steinwender, ${ }^{b}$ Bert T. G. Lutz, ${ }^{b}$ Joop H. van der Maas ${ }^{b}$ and \\ David N. Reinhoudt *,a \\ a Laboratory of Organic Chemistry, University of Twente, P.O. Box 217, 7500 AE Enschede, \\ The Netherlands \\ ${ }^{b}$ Department of Analytical Molecular Spectrometry, University of Utrecht, P.O. Box 80083, 3508 TB \\ Utrecht, The Netherlands
}

The effect of the solvent on the conformations of unsubstituted $p$-tert-butylcalix [4]arene (1) and its methyl ethers 2-6 has been investigated by ${ }^{~} H$ NMR spectroscopy. The conformational distribution of the 1,2-dimethyl ether 4 and of the tetramethyl ether $\mathbf{6}$ is strongly influenced by the solvent used. The exact geometry of the cone conformation of the 1,3-dimethyl ether 3 and of the 1,2dimethyl ether 4 changes from distinct $C_{2}$ symmetry in $\mathrm{CCl}_{4}$ to close to $C_{4}$ symmetry in $\mathrm{CS}_{2}$. It seems that inclusion of a small solvent molecule $\left(e . g . \mathrm{CS}_{2}\right.$ ) in the cone conformation can take place. Spectra recorded at temperatures up to $125^{\circ} \mathrm{C}$ in $\mathrm{CDCl}_{2} \mathrm{CDCl}_{2}$ showed that the mono- and 1,3-di-methyl ethers are fixed in the cone conformation, whereas the unsubstituted calix [4]arene and the tetramethyl ether are flexible. These observations support a concerted mechanism for the cone-to-cone interconversion in 1, in which two or more phenol rings rotate simultaneously.

The hydrogen bonding in partially methylated calix [4]arenes was investigated by IR spectroscopy. In all calix[4]arenes with neighbouring hydroxy groups, a strong cooperativity effect of $80 \%$ or more was observed. The exact geometry of the cone conformation affects the strength of the hydrogen bonds, because it influences the $\mathrm{O}-\mathrm{H} \ldots \mathrm{O}$ angle in the calix[4]arene. The effect of the solvent on the geometry of the cone conformation is translated in differences of up to $79 \mathrm{~cm}^{-1}$ in the $\mathrm{OH}$-stretch frequencies for spectra recorded in $\mathrm{CCl}_{4}$ and in $\mathrm{CS}_{2}$.

Calix [4]arenes are macrocyclic compounds consisting of four phenol rings that are connected at the ortho positions by methylene groups. ${ }^{1}$ They are increasingly being employed as building blocks for molecules that are designed for special applications, which till now have mainly involved the complexation of cations and neutral molecules. ${ }^{1.2}$ Their popularity is partly due to the fact that they can exist in four distinct conformations, viz. the cone, the partial cone, the 1,2-alternate, and the 1,3-alternate (Fig. 1).

The unsubstituted p-tert-butylcalix[4]arene (1) adopts in the solid state a regular cone conformation with $C_{4}$ symmetry

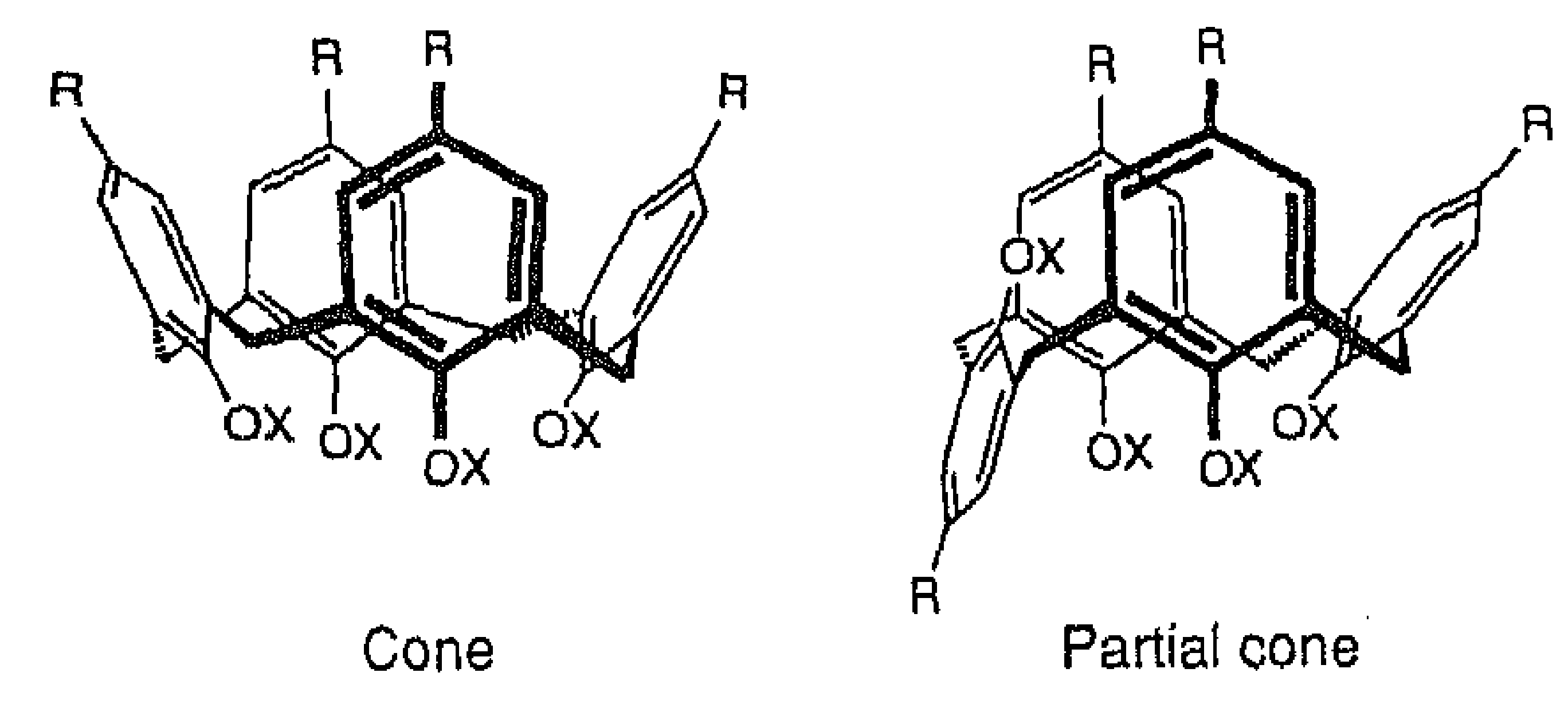

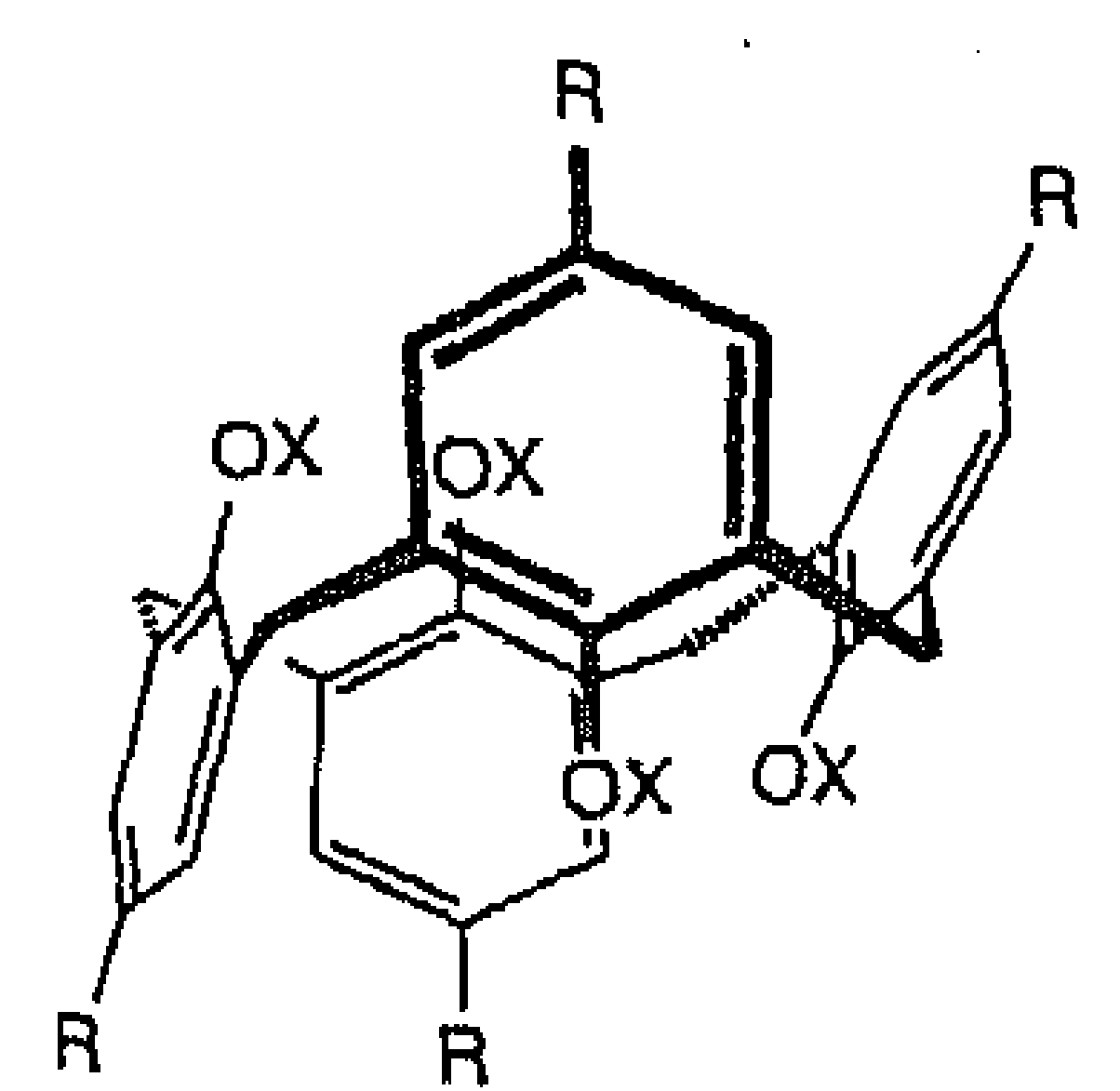

1, 2-Alternate

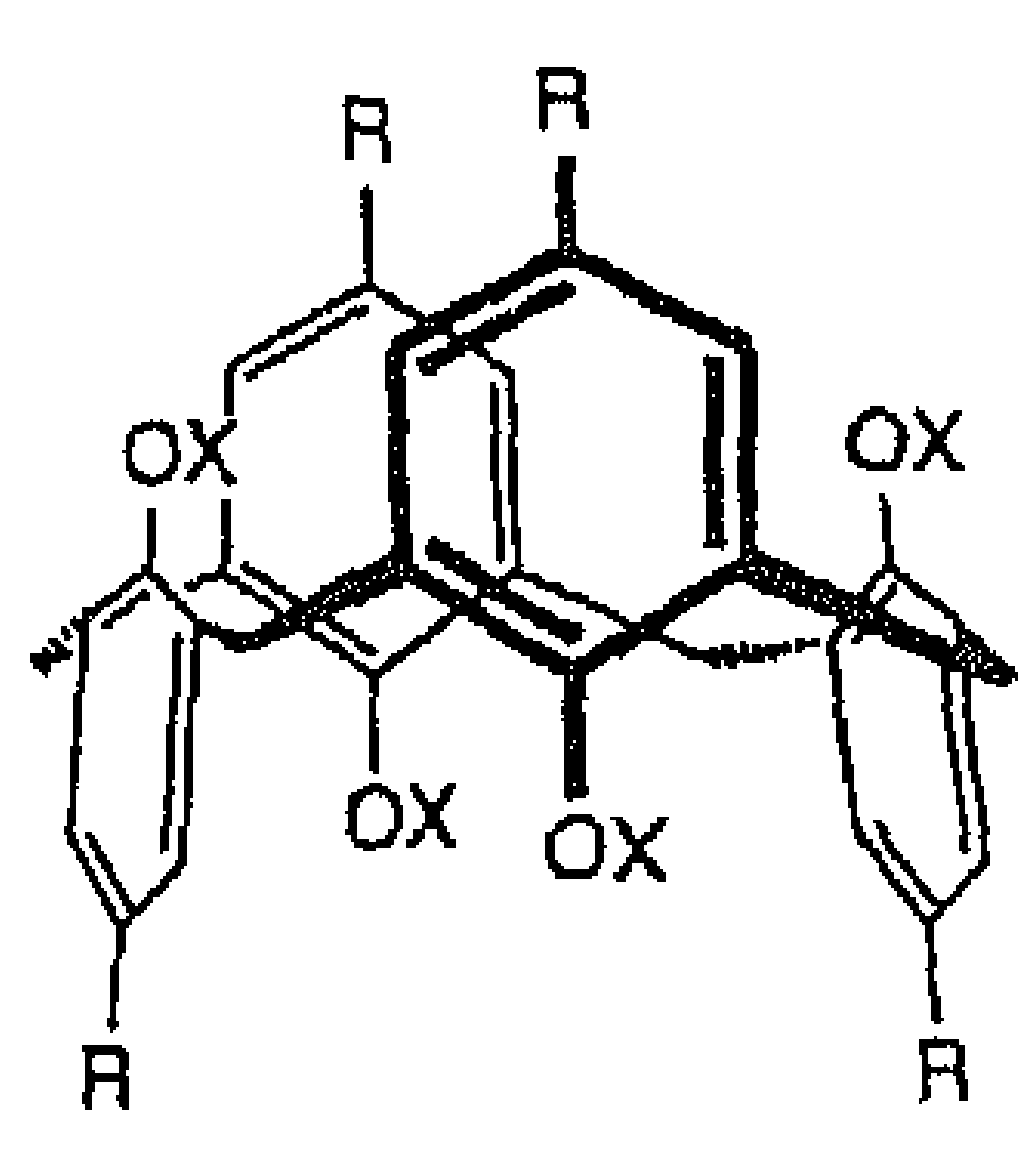

1, 3-Alternate
Fig. 1 The four main conformations of a calix[4]arene (toluene complex). ${ }^{3}$ At ambient temperature in solution compound 1 is flexible according to ${ }^{1} \mathrm{H}$ NMR spectroscopy but it is frozen out in the cone conformation upon cooling. ${ }^{4}$ This flexibility is due to the interconversion of the two mirror-image cone conformations. ${ }^{4}$ The cone is stabilized by an intramolecular array of very strong hydrogen bonds, as is evidenced by the very short $\mathrm{O} \ldots \mathrm{O}$ distances $(2.67 \AA)$ in the X-ray structure ${ }^{3}$ and the very low frequency $\left(3150 \mathrm{~cm}^{-1}\right)$ of the OH-stretch vibrations in the solid-state IR spectrum of the complex. ${ }^{4 a}$ The low frequency is indicative of a strong cooperativity effect in the hydrogen bonds. + It has been shown that in $\mathrm{CCl}_{4}$ solution the strength of the $\mathrm{H}$-bonds of calix [4]arenes that are bridged on two opposite para positions is considerably reduced when the $C_{4}$ symmetry of the cone is broken up to $C_{2}$ symmetry by shortening of the bridge. ${ }^{5}$

When large substituents are introduced on the four oxygen atoms, the conformation of the product is fixed, i.e., the isolated conformation cannot interconvert to other conformations. ${ }^{6}$ Thus, not necessarily the thermodynamically most stable conformation is formed, but rather the conformation that is favoured by the kinetics of the substitution reaction. Only the tetramethyl ether of p-tert-butylcalix[4]arene (6) is conformationally flexible at ambient temperature, which indicates that the methoxy group is small enough to allow rotation of the aromatic rings to take place. At low temperature, this compound exists as a mixture of all four possible conformations, of which the partial cone is the thermodynamically most stable conformation. ${ }^{7}$

As for both the unsubstituted calix[4]arene 1 and the

† The hydrogen bond of the first hydroxy group to a second hydroxy group will polarize the $\mathrm{OH}$ bond in this second hydroxy group, so that its hydrogen bond to a third oxygen atom is strengthened. For a recent article on $\mathrm{H}$-bond cooperativity see ref. 16. 
<smiles>[X]Oc1c(C)cc([R])cc1Cc1cc([R])cc(Cc2cc([R])cc(Cc3cc([R])cc(Cc4cc([R])cc([R])c4[X])c3[X])c2[R])c1[X]</smiles>

\begin{tabular}{l|lllll} 
& $\mathrm{R}$ & $\mathrm{X}^{1}$ & $\mathrm{X}^{2}$ & $\mathrm{X}^{3}$ & $\mathrm{X}^{4}$ \\
\hline $\mathbf{1}$ & $\mathrm{Bu}^{t}$ & $\mathrm{H}$ & $\mathrm{H}$ & $\mathrm{H}$ & $\mathrm{H}$ \\
2 & $\mathrm{Bu}^{t}$ & $\mathrm{Me}$ & $\mathrm{H}$ & $\mathrm{H}$ & $\mathrm{H}$ \\
3 & $\mathrm{Bu}^{t}$ & $\mathrm{Me}$ & $\mathrm{H}$ & $\mathrm{Me}$ & $\mathrm{H}$ \\
4 & $\mathrm{Bu}^{t}$ & $\mathrm{Me}$ & $\mathrm{Me}$ & $\mathrm{H}$ & $\mathrm{H}$ \\
$\mathbf{5}$ & $\mathrm{Bu}^{t}$ & $\mathrm{Me}$ & $\mathrm{Me}$ & $\mathrm{Me}$ & $\mathrm{H}$ \\
$\mathbf{6}$ & $\mathrm{Bu}^{t}$ & $\mathrm{Me}$ & $\mathrm{Me}$ & $\mathrm{Me}$ & $\mathrm{Me}$ \\
7 & $\mathrm{H}$ & $\mathrm{Me}$ & $\mathrm{H}$ & $\mathrm{Me}$ & $\mathrm{H}$
\end{tabular}

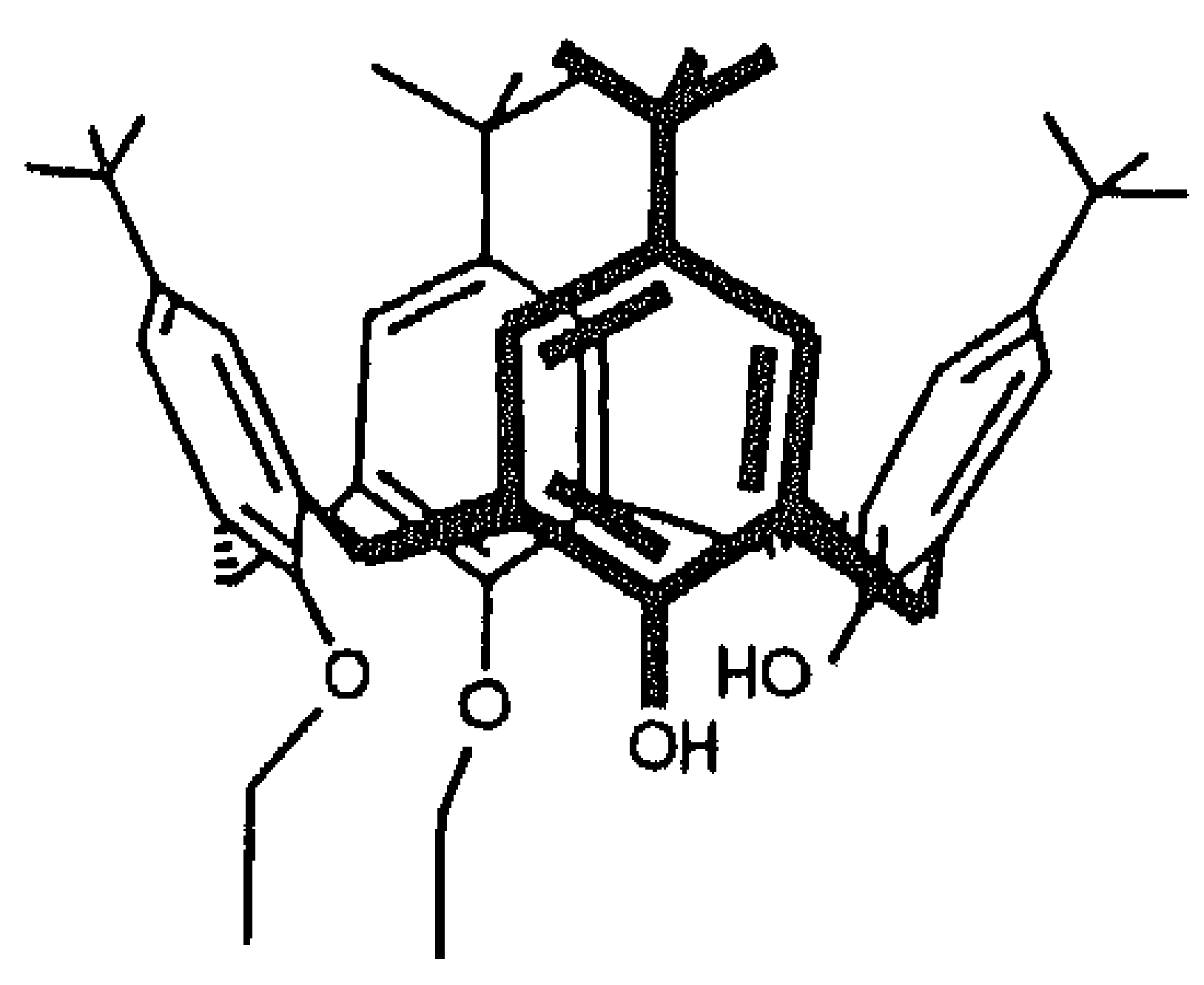

8

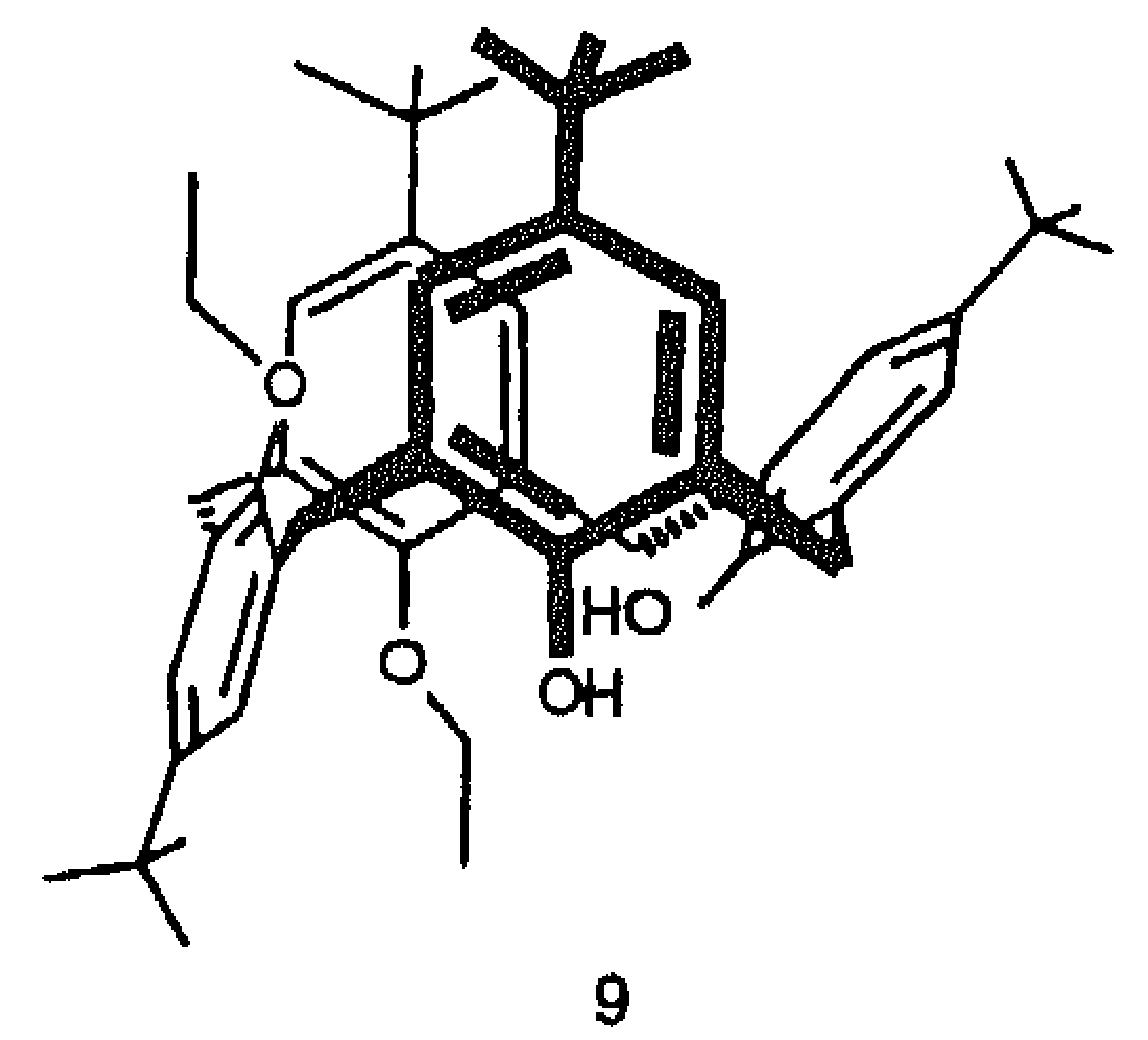

together with their X-ray structures. ${ }^{8}$ The electrostatic interactions (hydrogen bonding and oxygen-oxygen repulsion) were found to be the crucial factor for the determination of the conformation. The para-substituents (hydrogen or tert-butyl) have only a minor influence. Other authors have investigated the conformations of compounds $1,2,3$ and $5 \mathrm{in}^{\mathrm{CDCl}} \mathrm{CD}_{3}$ solution by NOE spectroscopy and concluded that all exist (mainly) in the cone conformation. ${ }^{9}$ The $\mathrm{OH}$-stretch frequencies (solidstate IR) and the $\mathrm{OH}$ signals $\left({ }^{1} \mathrm{H} \mathrm{NMR}\right.$ in $\left.\mathrm{CDCl}_{3}\right)$ of the same compounds have been related to the acidity of the hydroxy groups. ${ }^{10}$ Here we report the results of a detailed study of the hydrogen bonding structure and the conformations of partially methylated calix[4]arenes by IR and dynamic ${ }^{1} \mathrm{H}$ NMR spectroscopy, including experimental results for the 1,2-dimethyl ether 4, which has not been studied before. Furthermore, we present experimental evidence that the solvent can have a strong influence on the conformation of a calix[4]arene.

\section{Results}

The properties of $p$-tert-butylcalix[4]arene (1) have been well established by several research groups. ${ }^{3,4}$ We recorded the IR spectra of 1 in two different solvents and found a remarkable difference in the $\mathrm{OH}$-stretch frequencies. It has been reported to be $3138 \mathrm{~cm}^{-1}$ in $\mathrm{CCl}_{4},{ }^{11}$ but in $\mathrm{CS}_{2}$ the $\mathrm{OH}$-stretch vibration is found at $3190 \mathrm{~cm}^{-1}$ (see Table 1 ).

The monomethyl ether of $p$-tert-butylcalix[4]arene (2) exists in a cone conformation in $\mathrm{CDCl}_{3}$ solution. ${ }^{9}$ In the solid-state IR spectrum of 2 there are two $\mathrm{OH}$ bands present, a broad one at $3142 \mathrm{~cm}^{-1}$ and a narrower one at $3270 \mathrm{~cm}^{-1}$ (Table 1). ${ }^{10,12}$ At low temperature $(100 \mathrm{~K})$ these bands remain essentially the same although a shoulder becomes visible at $3309 \mathrm{~cm}^{-1}$ (Fig. 2). The second-derivative spectrum indicates that the broad band at $3129 \mathrm{~cm}^{-1}$ has two maxima at 3153 and $3110 \mathrm{~cm}^{-1}$. The IR spectrum of the partly deuteriated compound shows that the broad band in the OD region consists of two OD-strelch vibrations at slightly different wavenumber, as can be seen in the spectrum at $100 \mathrm{~K}$ (Fig. 2). In the OD region an extra 


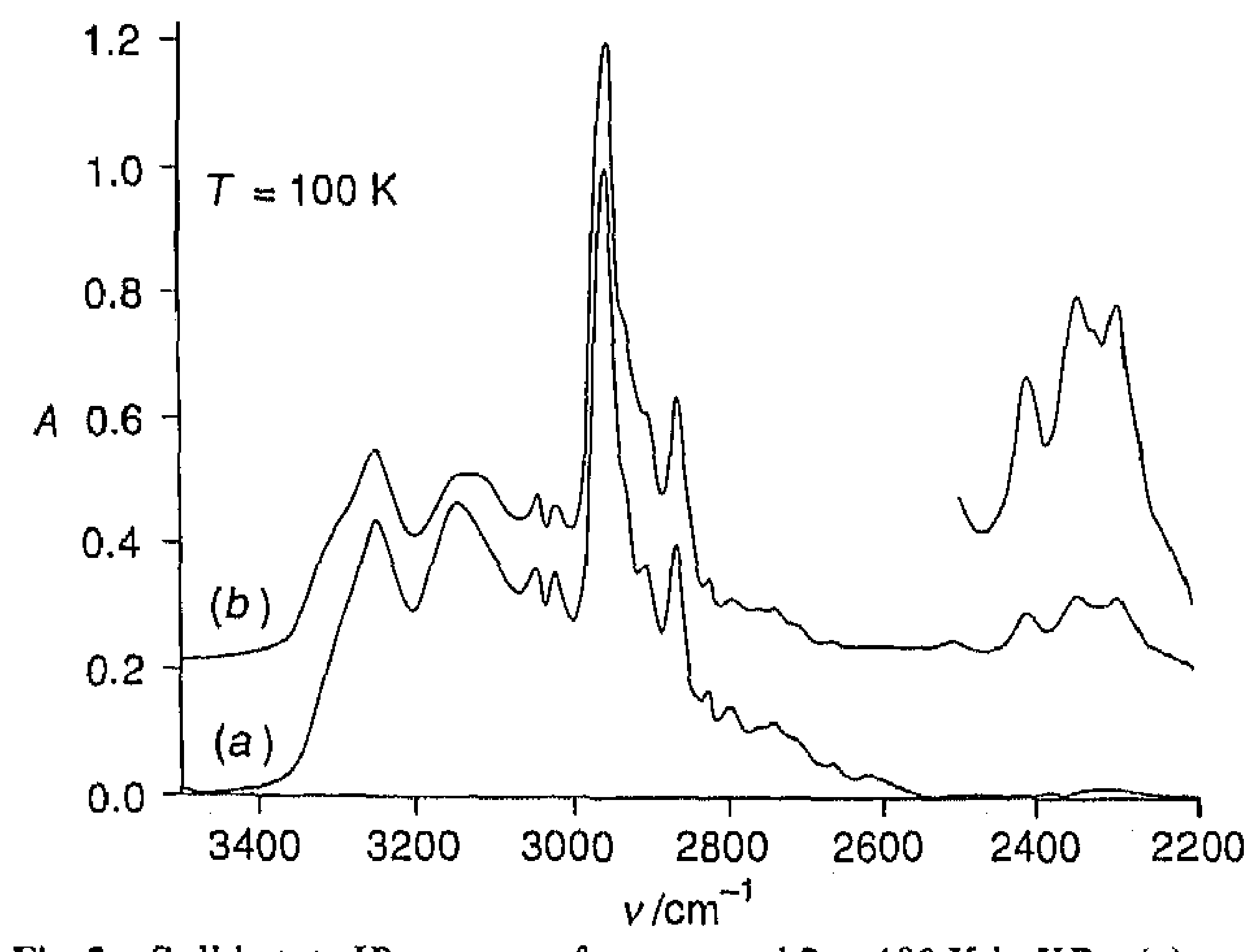

Fig. 2 Solid-state IR spectra of compound 2 at $100 \mathrm{~K}$ in $\mathrm{KBr},(a)$ nondeuteriated and $(b)$ partly deuteriated

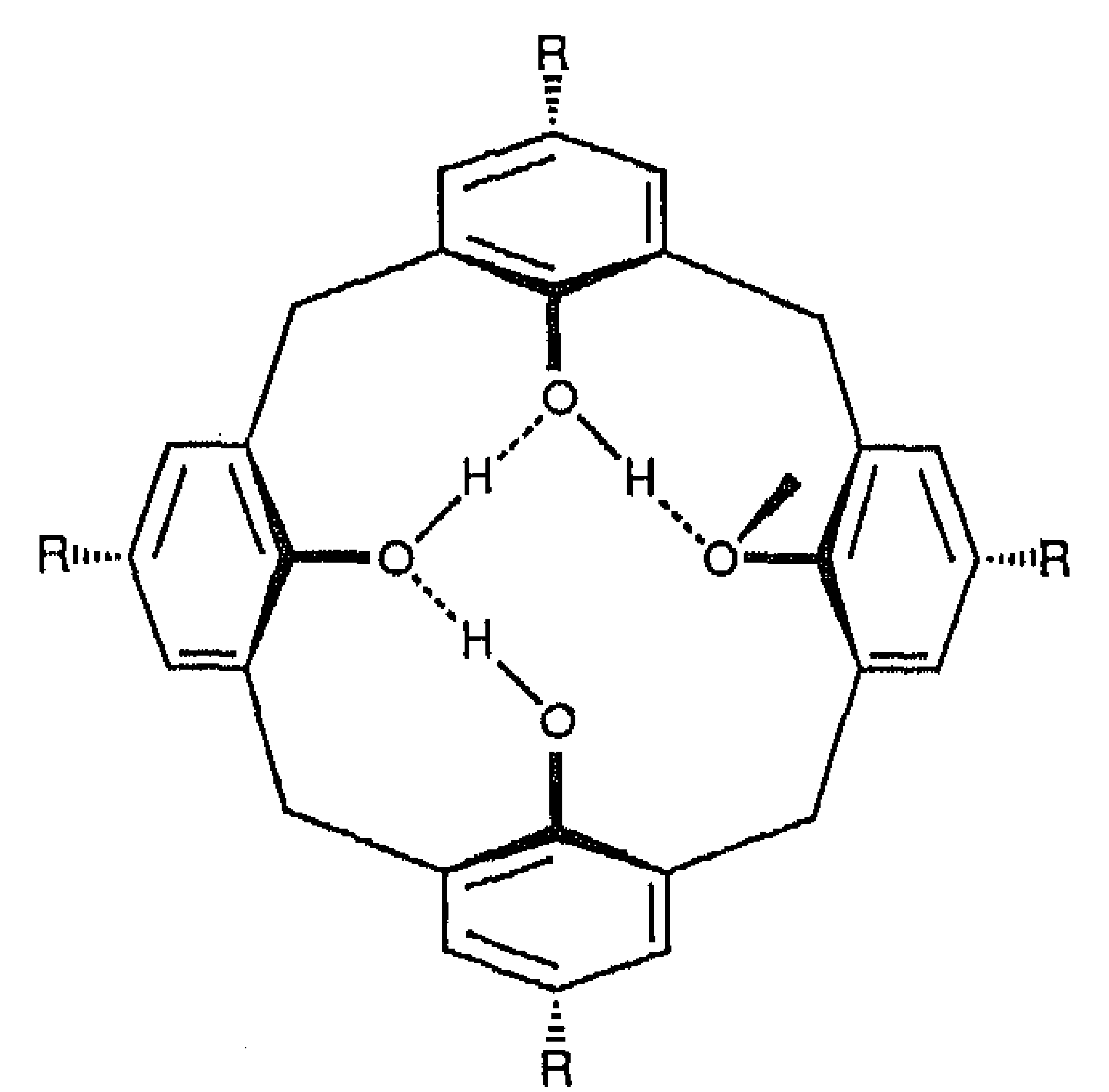

Fig. 3 The hydrogen bonding structure in the monomethyl ether 2

shoulder at the high-frequency side is not clearly visible, but instead another shoulder is present at $2324 \mathrm{~cm}^{-1}$. The isotope ratios of the three main $\mathrm{OH}$-stretch vibrations are 1.34-1.35. The presence of two strong hydrogen bonds and a weaker one is commensurate with a cone conformation with cooperative hydrogen bonds (Fig. 3). The extra shoulders might indicate that another $\mathrm{H}$-bonding geometry is present in the crystals. This could involve a reversal of the direction of the hydrogen bonds, which, in an asymmetrical cone like the cone predicted by molecular mechanics calculations, ${ }^{8}$ would lead to different $\mathrm{OH}$ stretch frequencies. Also in $\mathrm{CCl}_{4}$ and in $\mathrm{CS}_{2}$ solution three $\mathrm{OH}$ bands can be observed, two around $3200 \mathrm{~cm}^{-1}$, of which one is a shoulder on the other, and one at 3314 and $3343 \mathrm{~cm}^{-1}$, respectively.

In the ${ }^{1} \mathrm{H}$ NMR spectrum of 2 in $\mathrm{CDCl}_{3}$ there are two $\mathrm{OH}$ signals at $10.13(1 \mathrm{H})$ and $9.54 \mathrm{ppm}(2 \mathrm{H}) .{ }^{10,12}$ The ${ }^{1} \mathrm{H}$ NMR spectra in $\mathrm{CCl}_{4}$ and $\mathrm{CS}_{2}$ show the same characteristic pattern for the $\mathrm{OH}$ signals, which seems to indicate that there is only one strong $\mathrm{H}$ bond and two weaker ones. This seeming discrepancy between the IR and ${ }^{1} \mathrm{H}$ NMR spectra can be explained from the fact that with ${ }^{1} \mathrm{H}$ NMR spectroscopy one looks in a different time window than with IR spectroscopy. In this case, the ${ }^{1} \mathrm{H}$ NMR spectrum shows the averaged signals of two equivalent conformations, viz. one in which the $\mathrm{H}$-bonding scheme is as depicted in Fig. 3 and another in which the direction of the $\mathrm{H}$ bonds is reversed (flip-flop hydrogen bonding). ${ }^{8}$ Only the proton of the middle hydroxy group is in both cases involved in a strong cooperative $\mathrm{H}$ bond, whereas the two outer protons form half of the time a weaker $\mathrm{H}$ bond. Therefore, the middle proton will be more deshielded and its signal will be found at lower field than the signals of the two outer protons.

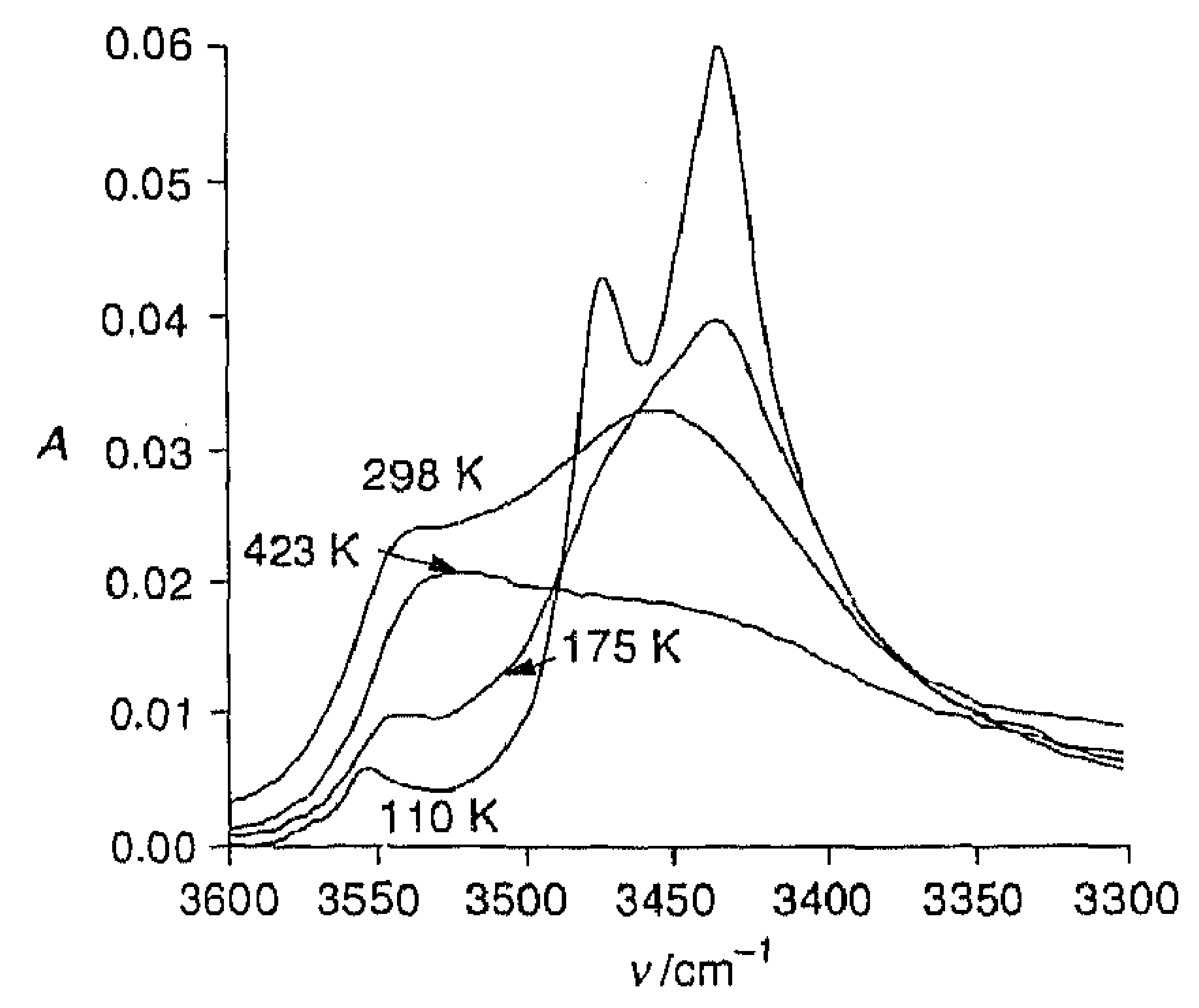

Fig. 4 Solid-state IR spectra of compound 3 in $\mathrm{KBr}$ at different temperatures between 100 and $500 \mathrm{~K}$

The ${ }^{1} \mathrm{H}$ NMR spectra that were recorded at higher temperatures (up to $125^{\circ} \mathrm{C}$ in $\mathrm{CDCl}_{2} \mathrm{CDCl}_{2}$ ) did not show any change in the conformation of 2 . Thus, by the introduction of just one methyl group in compound 1, the calix[4]arene is rigidified and the direct cone-to-cone interconversion is no longer possible.

Also the 1,3-dimethyl ether 3 adopts a cone conformation, both in solution ${ }^{66,9}$ and in the solid state, ${ }^{8}$ and does not show any sign of coalescence in its ${ }^{1} \mathrm{H}$ NMR spectrum at temperatures up to $125^{\circ} \mathrm{C}$ in $\mathrm{CDCl}_{2} \mathrm{CDCl}_{2}$. The IR spectrum of the solid state at ambient temperature shows an $\mathrm{OH}$ band at 3456 $\mathrm{cm}^{-1}$ with a shoulder at $3538 \mathrm{~cm}^{-1}$. The presence of the band at $3456 \mathrm{~cm}^{-1}$ indicates a rather weak hydrogen bond compared with unsubstituted calix [4]arenes. ${ }^{6 b .10}$ This is not so surprising as no cooperativity can exist in compound 3 and in fact the value of $3456 \mathrm{~cm}^{-1}$ is close to the value of $3470 \mathrm{~cm}^{-1}$ for the $\mathrm{H}$ bonded hydroxy group in $2,2^{\prime}$-methylenebisphenol in $\mathrm{CCl}_{4} .^{13}$ At low temperature the $\mathrm{OH}$ band at $3456 \mathrm{~cm}^{-1}$ is resolved into two separate bands at 3478 and $3435 \mathrm{~cm}^{-1}$ owing to the decrease of the half-widths (see Fig. 4). Furthermore, the secondderivative spectrum shows the presence of a shoulder at 3455 $\mathrm{cm}^{-1}$. The intensities of the $\mathrm{OH}$ bands are very sensitive to temperature. At $100 \mathrm{~K}$ the band at $3538 \mathrm{~cm}^{-1}$ has nearly disappeared, whereas it strongly increases at the cost of the band at $3456 \mathrm{~cm}^{-1}$ upon heating to $500 \mathrm{~K}$ (Fig. 4). This phenomenon is completely reversible between 100 and $500 \mathrm{~K}$. The two main $\mathrm{OH}$ bands at low temperature (at 3478 and 3435 $\mathrm{cm}^{-1}$ ) belong to the two hydroxy groups in 3 that are bonded to the anisole oxygen atoms. These $\mathrm{OH}$ groups are not equivalent because they are involved in different $\mathrm{OH} \ldots \mathrm{OCH}_{3}$ bonds in the solid state, as is obvious from the irregular cone conformation in the X-ray structure. ${ }^{8}$ The band at $3538 \mathrm{~cm}^{-1}$ (and the shoulder at $3455 \mathrm{~cm}^{-1}$ ) might belong to a second structure in which one or two of the hydrogen bonds are reversed. As these last two bands increase gradually with increasing temperature, it seems likely that an equilibrium exists between the two H-bonded structures, and that they differ only slightly in energy.

In $\mathrm{CCl}_{4}$ the $\mathrm{OH}$ band lies at $3423 \mathrm{~cm}^{-1}$, but surprisingly in $\mathrm{CS}_{2}$ this band is found at a $79 \mathrm{~cm}^{-1}$ lower frequency. Furthermore, in $\mathrm{CCl}_{4}$ two shoulders can be observed at the high-frequency side at 3539 and $3502 \mathrm{~cm}^{-1}$.

The solid-state IR spectrum of the 1,3-dimethyl ether of calix[4]arene (7) shows one $\mathrm{OH}$ band at $3384 \mathrm{~cm}^{-1}$, a much lower frequency than for compound 3. As for the p-tert-butyl analogue, this band is split in two separate bands at low temperature, in accordance with the irregular cone conformation in the X-ray structure of compound $7 .^{8}$ The IR spectrum of 7 
changes only slightly between 100 and $500 \mathrm{~K}$ and only at higher temperatures does an extra band at high frequency come up. The same equilibrium as for 3 might be involved but be less obvious for 7 because the energy difference between the two Hbond structures is larger. The absence of the tert-butyl groups in 7 also considerably reduces the solvent effect. The spectra in $\mathrm{CCl}_{4}$ and in $\mathrm{CS}_{2}$ show an $\mathrm{OH}$ band at nearly the same frequency ( 3365 and $3364 \mathrm{~cm}^{-1}$ ). In $\mathrm{CCl}_{4}$ there is again a shoulder present at $3535 \mathrm{~cm}^{-1}$.

The 1,2-dimethyl ether 4 is a structural isomer of the 1,3dimethyl ether. The ${ }^{1} \mathrm{H}$ NMR spectrum of 4 in $\mathrm{CDCl}_{3}$ at ambient temperature shows a complex pattern of signals that cannot be assigned to one conformation. Comparison with the spectra of the syn-1,2-diethyl ${ }^{14}$ and anti-1,2-diethyl ${ }^{7}$ ethers of p-tert-butylcalix [4] arene ( 8 and 9 , respectively) reveals that the spectrum of 4 can be regarded as a superposition of the spectra of compounds 8 and 9 (except for the signals of the ethyl substituents). Thus, the 1,2-dimethyl ether 4 exists in $\mathrm{CDCl}_{3}$ as a mixture of the cone (the syn form), and of two partial cones (with an anisole ring rotated through the cavity) that interconvert rapidly on the ${ }^{1} \mathrm{H}$ NMR time-scale (the anti form). ${ }^{15}$ The ratio between the syn and anti conformations depends strongly on the solvent. It ranges from 4.3:1 ( $\left.\mathrm{CS}_{2}\right)$, via 3.0:1 $\left(\mathrm{CDCl}_{3}\right)$ and $2.0: 1\left(\mathrm{CDCl}_{2} \mathrm{CDCl}_{2}\right)$, to $1.2: 1\left(\mathrm{CCl}_{4}\right)$. When a sample of 4 was heated in $\mathrm{CDCl}_{2} \mathrm{CDCl}_{2}$, broadening of the signals started at $105^{\circ} \mathrm{C}$. This implies that the signals are starting to coalesce, owing to the interconversion of the syn (cone) and the anti (partial cone) forms.

For both the cone and the partial cone one would expect a strong and a weak hydrogen bond, as in both conformations one cooperative $\mathrm{H}$ bond can be formed. Indeed, four different $\mathrm{OH}$ bands are present in $\mathrm{CS}_{2}$ but in $\mathrm{CCl}_{4}$ beside these four bands an extra band at $3506 \mathrm{~cm}^{-1}$ is observed (Table 1). This reflects the behaviour of the syn- and anti-1,2-diethyl ethers 8 and 9. ${ }^{15}$ In $\mathrm{CS}_{2}$ both compounds show only two $\mathrm{OH}$ bands, but in $\mathrm{CCl}_{4}$ the $s y n$-1,2-diethyl ether 8 shows two additional bands at 3525 and $3468 \mathrm{~cm}^{-1}$, probably belonging to another conformation without cooperative $\mathrm{H}$ bonds. ${ }^{15}$ In the solid state the IR spectrum of 4 shows only two bands at 3438 and 3367 $\mathrm{cm}^{-1}$. This indicates that compound 4 crystallizes in a conformation in which two different hydrogen bonds to oxygen atoms are present, but which is not the cone or the partial cone because these would give rise to lower frequencies, as in solution. The most likely conformation is a 1,2-alternate with a hydroxy and a methoxy group on each side of the ring. Unfortunately, it has not been possible to obtain crystals suitable for X-ray crystallography in order to check this hypothesis.

The trimethyl ether 5 crystallizes in the cone conformation ${ }^{8}$ and the solid-state IR spectrum shows one $\mathrm{OH}$ band at 3452 $\mathrm{cm}^{-1}$, in accord with a hydrogen bond to another oxygen atom. ${ }^{10}$ In $\mathrm{CDCl}_{3}$ solution the main conformation is the cone. ${ }^{9}$ Other conformations are present as well but these have until now not been identified with certainty. The ${ }^{1} \mathrm{H}$ NMR spectra that were recorded in other solvents (the same as for compound 4) did not change the relative populations of the conformations enough to render assignment of other conformations possible. Dynamic ${ }^{1} \mathrm{H} \mathrm{NMR}$ spectroscopy in $\mathrm{CDCl}_{2} \mathrm{CDCl}_{2}$ showed that already at $45^{\circ} \mathrm{C}$ broadening of signals takes place. At $125^{\circ} \mathrm{C}$ full coalescence has nearly been reached. The trimethyl ether is apparently more flexible than the 1,2-dimethyl ether.

The IR spectra in $\mathrm{CCl}_{4}$ and $\mathrm{CS}_{2}$ show two $\mathrm{OH}$ bands (see Table 1). The band at low frequency can be assigned to the cone conformation ( $c f$. the solid-state spectrum), and the band at $3520 \mathrm{~cm}^{-1}$ probably belongs to an $\mathrm{OH}$ group of another conformation. Remarkable is the difference of $55 \mathrm{~cm}^{-1}$ between the frequencies of the low-frequency $\mathrm{OH}$ band in $\mathrm{CCl}_{4}$ and in $\mathrm{CS}_{2}$
Table 2 Relative concentrations (in \%) of the conformations of tetramethyl ether 6 in different solvents $\left({ }^{1} \mathrm{H}\right.$ NMR, $200 \mathrm{MHz},-30^{\circ} \mathrm{C}$ )

\begin{tabular}{lclll}
\hline Solvent & Cone & $\begin{array}{l}\text { Partial } \\
\text { cone }\end{array}$ & 1,2-Alternate & 1,3-Alternate \\
\hline $\mathrm{CDCl}_{3}$ & 5 & 85 & 7 & 3 \\
$\mathrm{CS}_{2}\left(-15^{\circ} \mathrm{C}\right)$ & 14 & 81 & 5 & $<3$ \\
$\mathrm{CCl}_{4}$ & 14 & 77 & 9 & $<3$ \\
$\mathrm{CD}_{2} \mathrm{Cl}_{2}\left(-27^{\circ} \mathrm{C}\right)$ & 18 & 74 & 8 & $<3$ \\
\hline
\end{tabular}

The ${ }^{1} \mathrm{H}$ NMR spectrum of the tetramethyl ether of p-terfbutylcalix[4]arene (6) in $\mathrm{CDCl}_{3}$ at $-30{ }^{\circ} \mathrm{C}$ (recorded at 600 $\mathrm{MHz}$ ) has revealed that all four conformations are present in solution. Beside the partial cone $(85 \%)$, the cone $(4 \%)$, the 1,2 . alternate $(8 \%)$, and the 1,3 -alternate $(3 \%)$ are also present. Spectra recorded at $-30^{\circ} \mathrm{C}$ at $200 \mathrm{MHz}$ in several solvents showed large variations in the relative populations of the conformations (see Table 2). The spectra recorded at higher temperature (in $\mathrm{CDCl}_{2} \mathrm{CDCl}_{2}$ ) indicate that the tetramethyl ether is more flexible than the trimethyl ether. Already at $85^{\circ} \mathrm{C}$ the same degree of coalescence has been reached as for the trimethyl ether at $125^{\circ} \mathrm{C}$.

\section{Discussion}

The IR spectra of the methyl ethers of p-tert-butylcalix[4]arene show that the cooperativity in the hydrogen bonding in calix [4]arenes is very strong. The cooperativity is often expressed as the extra shift in the frequency of an $\mathrm{OH}$ group that is involved in a cooperative $\mathrm{H}$ bond relative to the frequency shift of an $\mathrm{OH}$ band in a non-cooperative $\mathrm{H}$ bond. ${ }^{16}$ As reference compounds 2,6-dimethyl-p-tert-butylphenol (3622 $\mathrm{cm}^{-1}$ in $\mathrm{CCl}_{4}$ and $3611 \mathrm{~cm}^{-1}$ in $\left.\mathrm{CS}_{2}\right)^{13}$ and the trimethyl ether 5 are used. The cooperativities amount to 150,130 and $125 \%$ in $\mathrm{CCl}_{4}$ for calixarenes 1,2 and 4 , respectively, and to $80 \%$ for all three compounds in $\mathrm{CS}_{2}$. The cooperativity is exceptionally strong compared with values given in the literature. ${ }^{16}$ This might be due to the phenolic character of the hydroxy groups and the strict intramolecular character of the $\mathrm{H}$ bonds. The differences between $\mathrm{CCl}_{4}$ and $\mathrm{CS}_{2}$ will be discussed below.

The strength of the hydrogen bonds of the calix[4] arenes in the solid state cannot simply be correlated to the $O \ldots O$ distances in the crystal. The shortest $\mathrm{O} \cdots \mathrm{O}$ distances are 2.67 $\AA$ (compound 1), 2.82 and $3.00 \AA$ (3), $2.96 \AA$ (5), and 2.86 and $2.90 \AA(7){ }^{8}$ Most pronounced are the discrepancies between the two 1,3-dimethyl ethers 3 and 7. The shortest distance is lound in compound 3 , but the lowest $\mathrm{OH}$ frequency (at $100 \mathrm{~K}$ ) for 3 is $66 \mathrm{~cm}^{-1}$ higher than for 7. This is too much to be an effect only of the different para substituents. * Apparently, the geometry of the $\mathrm{H}$ bonds plays a large role in these molecules, as has also been observed for the para-bridged calix[4]arenes. ${ }^{5}$ In a symmetrical cone (with $C_{4}$ symmetry as in 1) all four oxygen atoms lie exactly in one plane, which is parallel to the mean plane of the methylene carbon atoms. ${ }^{8}$ In a flattened cone (with $C_{2}$ symmetry, as for 3,5 and 7$),{ }^{8}$ two opposite anisole rings are nearly perpendicular to the plane of the methylene carbon atoms and the other two aromatic rings are rotated inwards so that the dihedral angles with the methylene plane are between 35 and $50^{\circ}$. The oxygen atoms are not in one plane, the anisole oxygens (of 3) lie $0.25 \AA$ below the mean plane, and the hydroxy oxygen atoms $0.25 \AA$ above it. For compound 7 these values are $0.20 \AA$. In these structures the $\mathrm{H}$ bonds deviate considerably

* In $\mathrm{CS}_{2}$ the $\mathrm{OH}$-stretch frequencies for 2,6-dimethylphenol and 4-ieributyl-2,6-dimethylphenol are $3610.5 \mathrm{~cm}^{-1}$ for both compounds. In $\mathrm{CCl}_{4}$ the frequencies are 3621.0 and $3622.0 \mathrm{~cm}^{-1}$, respectively (ref. 13). 
from linearity. The deviation from linearity is more pronounced in 3 than in 7, which may explain the stronger hydrogen bonds in 7 .

The differences between the $\mathrm{OH}$-stretch frequencies in $\mathrm{CS}_{2}$ and in $\mathrm{CCl}_{4}$ are too large and irregular to be explained by only the intrinsic properties of the solvent. More information about the phenomena that occur in solution can be obtained from the ${ }^{2} \mathrm{H}$ NMR spectra. First, the solvent influences the relative amounts of the conformations of the 1,2-dimethyl ether 4 and the tetramethyl ether 6 . Unfortunately, there is not a clear trend observable. Shinkai et al. have suggested that for 6 a conformation with a high dipole moment (cone) is stabilized relative to the partial cone in more polar solvents. ${ }^{17}$ However, this explanation does not cover all data presented here (e.g. for 6 there is more cone in $\mathrm{CCl}_{4}$ than in $\mathrm{CDCl}_{3}$, although $\mathrm{CDCl}_{3}$ is the more polar solvent). Another possible explanation is that the cone can be stabilized by inclusion of a solvent molecule in the cavity. In particular, a small molecule like $\mathrm{CS}_{2}$ can easily enter the cavity of the cone. Although no complexes of calix[4] arenes with $\mathrm{CS}_{2}$ are known, complexes of calix[4]arenes with other solvents (e.g. acetonitrile, toluene and acetone) in the solid state are known, ${ }^{1}$ as well as complexes of cone-shaped Högberg compounds with $\mathrm{CS}_{2} \cdot{ }^{18}$ However, this effect cannot provide an explanation for all the data for compounds 4 and 6.

An additional effect of the complexation of a solvent molecule in the cavity of a cone may be that the cone becomes more symmetrical (if it was a flattened cone before). This is apparent from the differences in the ${ }^{1} \mathrm{H}$ NMR spectra of compounds 3 and 4 in $\mathrm{CCl}_{4}$ and in $\mathrm{CS}_{2}$. The two tert-butyl signals of 3 are $0.46 \mathrm{ppm}$ apart in $\mathrm{CCl}_{4}$ but only $0.12 \mathrm{ppm}$ in $\mathrm{CS}_{2}$. For the cone of 4 these values are 0.08 and $0.01 \mathrm{ppm}$. Similar differences are also observed for the two aromatic signals of 3 . The degree of symmetry of the cone influences the relative positions of the oxygen atoms and thereby the strength of the $\mathrm{H}$ bonds (see above).

With the assumption that $\mathrm{CS}_{2}$ can form a relatively strong complex with the cone conformation but $\mathrm{CCl}_{4}$ cannot, many of the differences between the IR spectra in $\mathrm{CCl}_{4}$ and in $\mathrm{CS}_{2}$ can be explained. The simplest spectra are those of the 1,3-dimethyl ether of calix[4]arene (7). The $\mathrm{OH}$ band is not influenced by the solvent because the cone of this compound without parasubstituents has no appreciable cavity in which complexation can take place. For the p-tert-butyl analogue 3 the $79 \mathrm{~cm}^{-1}$ difference in the $\mathrm{OH}$ frequencies in $\mathrm{CCl}_{4}$ and $\mathrm{CS}_{2}$ can now be explained by the much stronger complexation of $\mathrm{CS}_{2}$ in the cavity of the cone. The cone in the complex is closer to $C_{4}$ symmetry than the empty cone, which has $C_{2}$ symmetry as in the $\mathrm{X}$-ray structure, and this changed geometry influences the strength of the $\mathrm{H}$ bonds. The extra $\mathrm{OH}$ bands that appear in the IR spectra in $\mathrm{CCl}_{4}$ must be due to one or more other $\mathrm{H}$-bond structures. These might involve other conformations of the calixarene, or a changed geometry of the cone (e.g. a second 'flattened' cone in which the two phenol groups are parallel). This phenomenon will be the subject of a future research project.

Similar, but smaller, frequency shifts are apparent in the IR spectra of the 1,2-dimethyl ether 4. The appearance of extra signals in $\mathrm{CCl}_{4}$ also indicates for this compound the presence of other $\mathrm{H}$-bond structures. Also for the trimethyl ether 5 a frequency difference is observed for the $\mathrm{OH}$ band that is assigned to the cone conformation. Both in $\mathrm{CCl}_{4}$ and in $\mathrm{CS}_{2}$ at least one other conformation is present according to the ${ }^{1} \mathrm{H}$ NMR spectra, which may account for the extra $\mathrm{OH}$ band at $3520 \mathrm{~cm}^{-1}$.

Surprisingly, the situation is reversed for the unsubstituted calix[4]arene 1 and the monomethyl ether 2, in that the $\mathrm{OH}$ frequencies in $\mathrm{CS}_{2}$ are higher than in $\mathrm{CCl}_{4}$. As there is no reason to exclude complexation in these compounds, the inclusion of a $\mathrm{CS}_{2}$ molecule in the cavity apparently changes the cone in a way that weakens the hydrogen bonds. Possibly, the symmetry of the cone of these compounds is reduced upon complexation of $\mathrm{CS}_{2}$. However, no indication for this was apparent from the ${ }^{1} \mathrm{H}$ NMR spectra of 2 in $\mathrm{CS}_{2}$ and in $\mathrm{CCl}_{4}$.

The differences in the cooperativity effects in $\mathrm{CCl}_{4}$ and in $\mathrm{CS}_{2}$ can now also be discussed. In $\mathrm{CS}_{2}$ the cone conformations of 1 , 2, 4 and 5 will be similar due to the complexation of a solvent molecule. The unexpected result is that maximum cooperativity is already reached when the first extra $\mathrm{H}$ bond is introduced. This might indicate that the geometry is not optimal for hydrogen bonding (which is obvious from the much lower frequency for 1 in $\mathrm{CCl}_{4}$ ). In $\mathrm{CCl}_{4}$, on the contrary, no complexation takes place and the strength of the $\mathrm{H}$ bonds is therefore also influenced by the changing geometries of the cone. Going from the trimethyl ether back to the unsubstituted calix[4]arene the cone is likely to become closer to $C_{4}$ symmetry. It is therefore difficult to assess the 'true' value of the cooperativity of the one, two or three extra $\mathrm{H}$ bonds in calix[4]arenes.

The dynamical behaviour of the calix[4]arenes $1-6$ is also very intriguing. Both unsubstituted p-tert-butylcalix[4]arene 1 and its tetramethyl ether 6 are flexible molecules and their ${ }^{1} \mathrm{H}$ NMR spectra exhibit broad signals at ambient temperature (in $\mathrm{CDCl}_{3}$ ). However, the ${ }^{1} \mathrm{H}$ NMR spectra of the partially methylated calix[4]arenes show only sharp signals at ambient temperature. The introduction of just one methyl group in unsubstituted $p$-tert-butylcalix[4]arene completely blocks the cone-to-cone interconversion, although this compound (2) can still exist in two equivalent cone conformations. Therefore, the process in 1 must involve the rotation of more than one aromatic ring at the same time. If only one aromatic ring rotated this process should also take place in 2 , because the rotation of one anisole ring at a time is possible in 6. ${ }^{7,19}$ Apparently, the concerted interconversion process in 1 is blocked by the methoxy group because of steric hindrance. These results are not sufficient to decide on the exact mechanism of the process, whether this involves a direct cone-to-cone interconversion, ${ }^{4 c}$ or a pathway via a skewed 1,2-alternate-like intermediate ${ }^{4 b}$ or even via a 1,3-alternate-like intermediate. ${ }^{4 a}$

For the 1,3-dimethyl ether the cone-to-cone interconversion is blocked for the same reason as for 2. The 1,2-dimethyl ether has two different conformations that are close in energy (syn and anti). The two equivalent partial cone conformations can interconvert fast at ambient temperature (leading to averaged signals in the ${ }^{1} \mathrm{H}$ NMR spectrum). This process requires the rotation of the two phenol rings so that one $\mathrm{H}$ bond must be broken. Interconversion between the two equivalent cone conformations does not take place. At higher temperatures broadening of the signals of cone and partial cone indicates that interconversion between cone and partial cone does take place. This would require the rotation of only one of the two anisole rings. The trimethyl ether is more flexible than the 1,2dimethyl ether and also exists in more than one conformation. These can interconvert by the rotation of one anisole ring at a time.

\section{Conclusions}

The strength of the hydrogen bonds in partly methylated calix [4] arenes in the cone conformation is influenced not only by the number of hydroxy groups (via the cooperativity effect) but also by the exact geometry of the cone. The conformational distribution of calix[4]arenes that exist in more than one conformation is strongly influenced by the solvent in which they are dissolved. Inclusion of a solvent molecule in the cone conformation also changes the geometry of the cone, which can 
have a pronounced effect (a shift of up to $79 \mathrm{~cm}^{-1}$ ) on the frequency of the $\mathrm{OH}$ bands in the IR spectra.

Also the flexibility of a calix[4] arene is strongly influenced by the number of oxygen substituents. The cone-to-cone interconversion in unsubstituted calix [4] arenes is completely blocked by the introduction of just one methyl group. As more methyl groups are introduced the calix[4]arene becomes flexible again. This lends support to a concerted mechanism for the interconversion in the unsubstituted calix[4]arene, in which two or more phenol rings rotate simultaneously, as opposed to the stepwise mechanism for the tetramethyl ether.

\section{Experimental}

The ${ }^{1} \mathrm{H}$ NMR spectra were recorded on a Nicolet NT 200-WB spectrometer $(200 \mathrm{MHz})$. The spectra in $\mathrm{CDCl}_{2} \mathrm{CDCl}_{2}$ were recorded at intervals of $20^{\circ} \mathrm{C}$ between 25 and $125^{\circ} \mathrm{C}$. The relative amounts of the conformations of compounds 4 and 6 in four different solvents were determined from the integrals of the methylene and methoxy signals for compound 4 and from the aromatic and methoxy signals for compound $\mathbf{6}$. As supplementary material copies of these eight spectra are available, together with a list of the signals of the spectra of compounds 2 , 3 and 4 in $\mathrm{CS}_{2}, \mathrm{CDCl}_{3}, \mathrm{CDCl}_{2} \mathrm{CDCl}_{2}$ and $\mathrm{CCl}_{4} \cdot{ }^{*}$

The variable temperature solid-state IR spectra $(\mathrm{KBr}$ and fluorolube) were recorded on a Mattson 5020 spectrophotometer connected to a personal computer at a resolution of 2 $\mathrm{cm}^{-1}$ by averaging 64 scans. The IR spectra in $\mathrm{CCl}_{4}$ and in $\mathrm{CS}_{2}$ were recorded with a Perkin-Elmer 1720, by using $1 \mathrm{~cm}$ Infrasil quartz cells, at a resolution of $2 \mathrm{~cm}^{-1}$ by averaging 50 scans. The concentration of the samples was less than $5 \times 10^{-3} \mathrm{~mol} \mathrm{dm}^{-3}$.

Compounds $1,{ }^{20} 2,{ }^{12} 3^{6 b} 6^{6 b}$ and $7^{21}$ were synthesized following literature procedures. Compound 5 was synthesized by reacting 6 with one equivalent of $\mathrm{Me}_{3} \mathrm{Sil}$ in $\mathrm{CHCl}_{3}$, following the same procedure as for the synthesis of $2 .^{12}$ Full characterization of this compound has been published by others. ${ }^{10}$ Several methods for the synthesis of 1,2-dimethyl ether 4 have been mentioned in the literature without a description of the full experimental procedure. ${ }^{14.22}$ One of these is described here in detail. ${ }^{14}$

27,28-Dimethoxy-p-tert-buty/calix[4]arene-25,26-diol 4. A suspension of p-tert-butylcalix [4] arene 1 (toluene complex, 0.25 g, $0.38 \mathrm{mmol})$ and $\mathrm{NaH}(80 \%$ in oil, $0.11 \mathrm{~g}, 4.75 \mathrm{mmol})$ in DMF $\left(10 \mathrm{~cm}^{3}\right)$ was stirred at room temperature for $0.5 \mathrm{~h}$. The alkylating agent $(0.8 \mathrm{mmol})$ was added and the reaction mixture was stirred for $16 \mathrm{~h}$. The reaction was quenched by addition of $\mathrm{HCl}\left(1 \mathrm{~mol} \mathrm{dm}-3 ; 20 \mathrm{~cm}^{3}\right)$ and the resulting mixture was extracted with $\mathrm{CH}_{2} \mathrm{Cl}_{2}\left(2 \times 20 \mathrm{~cm}^{3}\right)$. The combined organic layers were washed with $\mathrm{HCl}\left(1 \mathrm{~mol} \mathrm{dm} \mathrm{m}^{-3} ; 25 \mathrm{~cm}^{3}\right)$ and $\mathrm{H}_{2} \mathrm{O}(25$ $\mathrm{cm}^{3}$ ), dried over $\mathrm{MgSO}_{4}$, and evaporated. Purification of the crude product by taking it up in ethyl acetate and filtering off the remaining starting material, and then column chromatography $\left[\mathrm{SiO}_{2}\right.$, E. Merck, particle size $0.040-0.063 \mathrm{~mm}, 230-400$ mesh, eluent $\mathrm{CH}_{2} \mathrm{Cl}_{2}$-light petroleum (b.p. $40-60^{\circ} \mathrm{C}$ ), $\left.3: 1\right]$ yielded 4 $\left(34 \%\right.$ ), m.p. $222-224{ }^{\circ} \mathrm{C}$ (from hexane) (Found: $\mathrm{C}, 81.2 ; \mathrm{H}, 8.75$. $\mathrm{C}_{46} \mathrm{H}_{60} \mathrm{O}_{4}$ requires $\left.\mathrm{C}, 81.6 ; \mathrm{H}, 8.93 \%\right) ; \delta_{\mathrm{H}}\left(250 \mathrm{MHz} ; \mathrm{CDCl}_{3}\right.$; $\left.\mathrm{Me}_{4} \mathrm{Si}\right) 8.60(2 \mathrm{H}, \mathrm{s}, \mathrm{OH}, \mathrm{syn}), 7.28(2 \mathrm{H}, \mathrm{s}, \mathrm{OH}$, anti $), 7.20-7.15$ $(4 \mathrm{H}, \mathrm{m}, \mathrm{ArH}$, anti $), 7.05-6.95(8 \mathrm{H}, \mathrm{m}, \mathrm{ArH}, s y n$, and $4 \mathrm{H}, \mathrm{m}$, ArH, anti), 4.39, $4.33\left(1 \mathrm{H}, \mathrm{d}, J 13.5 \mathrm{~Hz}, \mathrm{ArCH}_{2} \mathrm{Ar}\right.$ ax, syn), 4.31 $\left(2 \mathrm{H}, \mathrm{d}, J 13 \mathrm{~Hz}, \mathrm{ArCH}_{2} \mathrm{Ar}\right.$ ax, syn), $4.00\left(6 \mathrm{H}, \mathrm{s}, \mathrm{OCH}_{3}, s y n\right)$, 3.95, $3.71\left(2 \mathrm{H}, \mathrm{s}, \mathrm{ArCH}_{2} \mathrm{Ar}\right.$, anti), 3.87 and $3.69(4 \mathrm{H}, \mathrm{AB}$ system,

* Supp. Pub. No. 56900, 10 pp. For details of the supplementary publications scheme, see 'Instructions for Authors (1992).' J. Chem. Soc., Perkin Trans. 2, 1992, issue 1.
$J 13 \mathrm{~Hz}, \mathrm{ArCH}_{2} \mathrm{Ar}$, anti), $3.36\left(3 \mathrm{H}, \mathrm{d}, J 13 \mathrm{~Hz}, \mathrm{ArCH}_{2} \mathrm{Areq}\right.$, syn), $3.34\left(1 \mathrm{H}, \mathrm{d}, J 13.5 \mathrm{~Hz}, \mathrm{ArCH}_{2} \mathrm{Ar}\right.$ eq, syn), $2.94(6 \mathrm{H}, \mathrm{s}$, $\mathrm{OCH}_{3}$, anti $), 1.30,1.22\left[18 \mathrm{H}, \mathrm{s}, \mathrm{C}\left(\mathrm{CH}_{3}\right)_{3}\right.$, anti $], 1.19,1.13[18$ $\left.\mathrm{H}, \mathrm{s}, \mathrm{C}\left(\mathrm{CH}_{3}\right)_{3}, \mathrm{syn}\right] ; m / z(\mathrm{FAB}+) 677\left(\mathrm{M}^{+}\right)$.

\section{Acknowledgements}

Dr. Fred Singelenberg is gratefully acknowledged for stimulating discussions. Marco Rietveld and Hubert de Leeww ate thanked for recording FT-IR spectra and Mrs. Hanny Visser fot recording many of the ${ }^{1} \mathrm{H}$ NMR spectra. This research was partly supported by the Netherlands Foundation for Chemical Research (SON) with financial aid from the Netherlands Organization for Scientific Research (NWO).

\section{References}

1 (a) C. D. Gutsche, Calixarenes, Royal Society of Chemistry, Cambridge, 1989; (b) Calixarenes. A Versatile Class of Compondu, eds. J. Vicens and V. Böhmer, Kluwer Academic Publishters Dordrecht, 1991.

2 L. C. Groenen and D. N. Reinhoudt, Supramolecular Chemistry, eds V. Balzani and L. de Cola, Kluwer Academic Publishers, Dordrechl, 1991, p. 51.

3 G. D. Andreetti, R. Ungaro and A. Pochini, J. Chem. Soc., Chem. Commun., 1979, 1005.

4 (a) G. Happel, B. Mathiasch and H. Kämmerer, Makromol. Chom, $1975,176,3317 ;(b)$ C. D. Gutsche and L. J. Bauer, J. Am. Chkm. Som 1985, 107, 6052; (c) K. Araki, S. Shinkai and T. Matsuda, Chem. Leth $1989,581$.

5 V. Böhmer, H. Goldmann, W. Vogt, E. F. Paulus, F. L. Tobialson and M. J. Thielman, J. Chem. Soc., Perkin Trans. 2, 1990, 1769.

6 (a) V. Bocchi, D. Foina, A. Pochini, R. Ungaro and G. D. Andreetiti, Tetrahedron, 1982, 38, 373; (b) C. D. Gutsche, B. Dhawun, J, A. Levine, K. H. No and L. J. Bauer, Tetrahedron, 1983, 39, 409.

7 L. C. Groenen, J.-D. van Loon, W. Verboom, S. Harkemil, A Casnati, R. Ungaro, A. Pochini, F. Ugozzoli and D. N. Reinhouou, J. Am. Chem. Soc., 1991, 113, 2385.

8 P. D. J. Grootenhuis, P. A. Kollman, L. C. Groenen, D. N Reinhoudt, G. J. van Hummel, F. Ugozzoli and G. D. Andreetti, J. Am. Chem. Soc., 1990, 112, 4165.

9 C. Alfieri, E. Dradi, A. Pochini and R. Ungaro, Gazz. Chim. Hal., 1989, 119, 335 .

10 K. Araki, K. Iwamoto, S. Shinkai and T. Matsuda, Bull. Chem. sor. Jpn., 1990, 63, 3480 .

11 S. W. Keller, G. M. Schuster and F. L. Tobiason, Polym. Matrr. Soi Eng., 1987, 57, 906.

12 A. Casnati, A. Arduini, E. Ghidini, A. Pochini and R. Unguro, Tetrahedron, 1991, 47, 2221.

13 E. T. G. Lutz and J. H. van der Maas, unpublished work.

14 L. C. Groenen, B. H. M. Ruël, A. Casnati, P. Timmerman, W. Verboom, S. Harkema, A. Pochini, R. Ungaro and D. N. Reinhoudt, Tetrahedron Lett., 1991, 32, 2675.

15 J. A. Kanters, A. Schouten, E. Steinwender, J. H. van der Muas, L. C. Groenen and D. N. Reinhoudt, J. Mol. Struct., 1991, 269, 49.

16 H. Kleeberg and W. A. P. Luck, Z. Phys. Chem. (Leipzig), 1989, 270, 613.

17 S. Shinkai, K. Iwamoto, K. Araki and T. Matsuda, Chem. Le'l, 1990, 1263.

18 (a) D. J. Cram, K. D. Stewart, I. Goldberg and K. N. Trueblood, J. Am. Chem. Soc., 1985, 107, 2574; (b) I. Goldberg, J. Indusion Phenom., 1986, 4, 191.

19 J.-D. van Loon, L. C. Groenen, W. Verboom, S. S. Wijmengi and D. N. Rcinhoudt, J. Am. Chem. Soc., 1991, 113, 2378.

20 C. D. Gutsche, M. Iqbal and D. Stewart, J. Org. Chem., 1986, 51, 742

21 J.-D. van Loon, A. Arduini, L. Coppi, W. Verboom, A. Pochitri. R. Ungaro, S. Harkema and D. N. Reinhoudt, J. Org. Chem., $1990_{+}$ 55, 5639.

22 A. Arduini, A. Casnati, L. Dodi, A. Pochini and R. Ungaro, J. Clem Soc., Chem. Commun., 1990, 1597.

Paper 2/0355013

Received 6th July 1992 Accepted 3rd August 1992 